\title{
Neoadjuvant Degarelix Versus Triptorelin in Premenopausal Patients Who Receive Letrozole for Locally Advanced Endocrine-Responsive Breast Cancer: A Randomized Phase II Trial
}

Silvia Dellapasqua, MD; Kathryn P. Gray, PhD²; Elisabetta Munzone, MD ${ }^{1}$; Daniela Rubino, MD³ Lorenzo Gianni, MD4; Harriet Johansson, PhD, MSc ${ }^{1}$; Giuseppe Viale, MD¹; Karin Ribi, PhD, MPH ${ }^{5}$; Jürg Bernhard, PhD ${ }^{5}$; Roswitha Kammler ${ }^{5}$; Rudolf Maibach, PhD Manuela Rabaglio-Poretti, MD5; Barbara Ruepp, PharmD5; Angelo Di Leo, MD, PhD; Alan S. Coates, MD7; Richard D. Gelber, PhD ${ }^{8,9}$; Meredith M. Regan, ScD ${ }^{9}$; Aron Goldhirsch, MD ${ }^{1}$; and Marco Colleoni, MD ${ }^{1}$, for the International Breast Cancer Study Group

ASSOCIATED CONTENT

Appendix

Data Supplement

Author affiliations

and support

information (if

applicable) appear

at the end of this

article.

Accepted on October 19, 2018 and published at jco.org on December 27, 2018: Dol https://doi. org/10.1200/JCO.18. 00296

Written on behalf of the International Breast Cancer Study Group.

The pharmaceutical company had no role in the reporting or interpretation of the trial other than the opportunity to review the manuscript before submission.

Clinical trial information: ClinicalTrials.gov NCT02005887; EudraCT, 2012-005326-29.

PURPOSE To evaluate endocrine activity in terms of ovarian function suppression (OFS) of degarelix (a gonadotropin-releasing hormone $[\mathrm{GnRH}]$ antagonist) versus triptorelin (a $\mathrm{GnRH}$ agonist) in premenopausal patients receiving letrozole as neoadjuvant endocrine therapy for breast cancer.

PATIENTS AND METHODS Premenopausal women with stage cT2 to 4b, any N, MO; estrogen receptor and progesterone receptor greater than 50\%; human epidermal growth factor receptor 2-negative breast cancer were randomly assigned to triptorelin $3.75 \mathrm{mg}$ administered intramuscularly on day 1 of every cycle or degarelix $240 \mathrm{mg}$ administered subcutaneously (SC) on day 1 of cycle 1 then $80 \mathrm{mg}$ SC on day 1 of cycles 2 through 6 , both with letrozole $2.5 \mathrm{mg} /$ day for six 28-day cycles. Surgery was performed 2 to 3 weeks after the last injection. Serum was collected at baseline, after 24 and 72 hours, at 7 and 14 days, and then before injections on cycles 2 through 6 . The primary end point was time to optimal OFS (time from the first injection to first assessment of centrally assessed estradiol level $\leq 2.72 \mathrm{pg} / \mathrm{mL}$ [ $\leq 10 \mathrm{pmol} / \mathrm{L}]$ during neoadjuvant therapy). The trial had $90 \%$ power to detect a difference using a log-rank test with a two-sided $\alpha$ of .05. Secondary end points included response, tolerability, and patient-reported endocrine symptoms.

RESULTS Between February 2014 and January 2017, 51 patients were enrolled ( $n=26$ received triptorelin plus letrozole; $n=25$ received degarelix plus letrozole). Time to optimal OFS was three times faster for patients assigned to degarelix and letrozole than to triptorelin and letrozole (median, 3 v 14 days; hazard ratio, 3.05; 95\% $\mathrm{Cl}, 1.65$ to 5.65; $P<.001$ ). Furthermore, OFS was maintained during subsequent cycles for all patients assigned to receive degarelix and letrozole, whereas $15.4 \%$ of patients assigned to receive triptorelin and letrozole had suboptimal OFS after cycle 1 (six events during 127 measurements). Adverse events as a result of both degarelix plus letrozole and triptorelin plus letrozole were as expected.

CONCLUSION In premenopausal women receiving letrozole for neoadjuvant endocrine therapy, OFS was achieved more quickly and maintained more effectively with degarelix than with triptorelin.

\section{J Clin Oncol 37:386-395. @ 2018 by American Society of Clinical Oncology}

\section{INTRODUCTION}

Ovarian function suppression (OFS) was the first form of systemic treatment for advanced breast cancer. ${ }^{1}$ Its use as an adjuvant therapy was associated with improved disease-free and overall survivals in patients younger than age 50 years who had breast cancer. ${ }^{2}$ Currently, for premenopausal patients with endocrineresponsive breast cancer, OFS is considered an important aspect of treatment in the advanced disease ${ }^{3}$ setting and in the adjuvant and neoadjuvant settings. ${ }^{4}$ Gonadotropin-releasing hormone (GnRH) analogs interact with the $\mathrm{GnRH}$ receptor and modify release of pituitary gonadotropins. Several GnRH analogs have been developed (eg, triptorelin, goserelin and leuprolide), and there are no apparent differences in their OFS capabilities. ${ }^{5}$ Upon administration of GnRH agonists, an initial stimulating action of the hypophysis occurs (flare effect), which eventually causes a sustained decrease in gonadotropin secretion (downregulation) that can be observed after approximately 10 days. For some patients, there can be a delay of 2 to 4 months until downregulation of the gonadotropins occurs. Moreover, approximately $20 \%$ of women do not maintain complete OFS with $\mathrm{GnRH}$ analogs ${ }^{6}$ and experience occasional elevations in estradiol (E2) as a result of sporadic escapes from OFS. 
Degarelix (Firmagon; Ferring, Copenhagen, DK) is a GnRH antagonist that binds to and blocks $\mathrm{GnRH}$ receptors in the pituitary gland, which results in decreased secretion of gonadotropins. In men, this leads directly to a rapid decrease in the production of testosterone, for which suppression to castration levels is achieved within 1 to 3 days and remains sustained during treatment. ${ }^{7,8}$ Degarelix is currently approved for the treatment of prostate cancer. Data are not available for the use of degarelix in patients with breast cancer.

In premenopausal women, suppression of ovarian function with degarelix might be faster than with $\mathrm{GnRH}$ analogs and optimally maintained throughout the treatment period. Neoadjuvant endocrine therapy (NET) is an excellent platform for the development of investigational drugs and the exploration of novel combinations that can be developed in other clinical settings. ${ }^{9}$

Limited data are available on NET in premenopausal patients. In the Neoadjuvant Anastrozole Versus Tamoxifen in Patients Receiving Goserelin for Premenopausal Breast Cancer (STAGE) trial, 204 premenopausal women were randomly assigned to receive goserelin $3.6 \mathrm{mg} / \mathrm{month}$ plus either anastrozole or tamoxifen for 24 weeks before surgery. More patients in the anastrozole group than in the tamoxifen group had a complete or partial response $(70.4 \% \mathrm{~V}$ $50.5 \%$, respectively). ${ }^{10}$

We therefore designed the TREND (Trial on the Endocrine activity of Neoadjuvant Degarelix) trial (International Breast Cancer Study Group [IBCSG] 41-13), an open-label, twoarm, phase II, randomized study, to compare the endocrine activity of triptorelin versus degarelix in premenopausal patients with breast cancer receiving letrozole as NET.

\section{PATIENTS AND METHODS}

\section{Patients}

Premenopausal women with histologically confirmed stage cT2 to 4b, any nodal stage, M0; estrogen (ER) and progesterone (PgR) receptor expression greater than 50\%; human epidermal growth factor receptor 2 (HER2)-negative (by immunohistochemistry and/or in situ hybridization); invasive breast cancer were eligible. Premenopausal status was determined locally as $17-\beta$-estradiol (ie, E2) levels greater than $54 \mathrm{pg} / \mathrm{mL}$ (or $>198 \mathrm{pmol} / \mathrm{L}$ ) measured within 14 days before random assignment. Patients could not have had a prior GnRH analog, a selective ER modulator or aromatase inhibitor (AI) within 12 months before random assignment, or used hormonal treatment (eg, oral, injectable, implanted contraceptive or medicated intrauterine device) in the 2 months before random assignment.

\section{Study Design}

Patients were randomly assigned in a 1:1 ratio to receive six 28-day cycles of NET with one of the following: triptorelin
$3.75 \mathrm{mg}$ intramuscularly on day 1 of every cycle plus letrozole $2.5 \mathrm{mg} /$ day orally; or degarelix $240 \mathrm{mg}$ subcutaneously given as two subcutaneous injections of $120 \mathrm{mg}$ on day 1 of cycle 1 followed by $80 \mathrm{mg}$ on day 1 of cycles 2 through 6 plus letrozole. Letrozole was started on day 1 , concurrent with triptorelin or degarelix. Trial treatments were to start within 14 days of random assignment and could be started at any time during the menstrual cycle. Definitive surgery was performed within 2 to 3 weeks after the last administration of triptorelin or degarelix. After postsurgery evaluation, no additional follow-up data were collected within the trial. Postsurgical treatments were given at the discretion of the investigator. Random assignment was stratified according to age at random assignment ( $\leq 39 v \geq 40$ years).

Study visits occurred before every 28-day cycle for 6 months and required a physical exam, an Eastern Cooperative Oncology Group performance status, weight, and collection of adverse events (AEs; 31 targeted AEs and other grades 3 to $4 \mathrm{AEs}$ according to Common Terminology Criteria for AEs, version 4.0). Tumor evaluation by bilateral mammography and breast ultrasound and laboratory tests (hematology, chemistry, carcinoembryonic antigen [CEA], cancer antigen 15.3 [CA15.3]) were required at baseline, after three cycles, and before surgery. Data about AEs and concomitant medications were also collected 30 days after surgery. Patients completed the 19-item Functional Assessment of Cancer Therapy, endocrine subscale (FACTES) at baseline, on day 1 of cycles 2 and 4 , and before surgery.

E2, follicle-stimulating hormone (FSH), and luteinizing hormone (LH) levels were determined in a central laboratory from serum samples collected at day 1 of the first treatment cycle before the administration of the first dose (baseline), at 24 and 72 hours, 7 days and 14 days after first injection, and on day 1 of cycles 2 through 6 . E2 concentrations were measured by gas chromatography tandem mass spectrometry detection after liquid-liquid extraction. Duplicate standard curves, water blanks, and four assay control pools were processed with samples to assess accuracy and precision of the assay. The lower limit of E2 level quantification was $0.625 \mathrm{pg} / \mathrm{mL}$. Central pathology review of diagnostic biopsy and of the residual surgical specimen was mandatory for this trial, but patients were included on the basis of tumor characteristics as determined by the local pathologist.

The primary end point was time to optimal OFS, calculated as the time from the first injection of degarelix or triptorelin until the first occurrence of a centrally assessed E2 level in the range of optimal OFS $(\leq 2.72 \mathrm{pg} / \mathrm{mL} \text { or } \leq 10 \mathrm{pmol} / \mathrm{L})^{11}$ during the six cycles of NET. Secondary end points included best overall response according to WHO response criteria, ${ }^{12}$ rate of node-negative disease at surgery, rate of breast-conserving surgery (BCS), preoperative endocrine prognostic index (PEPI) score, Ki-67 (protein encoded by 
the MKI67 gene) changes, and patient-reported endocrine symptoms (by FACT-ES summary score). ${ }^{13}$

The trial was conducted in three centers in Italy. The IBCSG coordinated the trial and is responsible for the study design, random assignment, collection and management of data, medical review, data analysis, and reporting. The trial was conducted in accordance with the provisions of the Declaration of Helsinki. The ethics committees at each center approved the study protocol, and all patients provided written informed consent. The IBCSG Data and Safety Monitoring Committee reviewed the trial twice yearly. Ferring donated the study drugs.

\section{Statistical Considerations}

Analyses were performed according to the intention-to-treat principle. Kaplan-Meier estimates of the cumulative proportions of patients who achieved optimal OFS were calculated. Cox proportional hazards regression and the logrank test, stratified according to age, were used to estimate the hazard ratio, $95 \% \mathrm{Cl}$, and $P$ value in a comparison of the time to optimal OFS between the two treatment groups.

The statistical design assumed that the cumulative percentages of patients with optimal OFS by 2, 4, 8, 12, and 16 weeks were $30 \%, 60 \%, 75 \%, 90 \%$, and $100 \%$ of patients, respectively, assigned to triptorelin plus letrozole and $60 \%, 95 \%, 100 \%, 100 \%$, and $100 \%$ of patients, respectively, assigned to degarelix plus letrozole. With 23 patients per group, the study had $90 \%$ power to detect a between-group difference in time to optimal OFS using a twosample log-rank test (two-sided $\alpha=.05$ ). The calculations were performed using nQuery Advisor (Statistical Solutions Ltd. 8 South Bank Crosse's Green Cork, Ireland) for the logrank test of survival in two groups (simulation with the aforementioned percentages specified). To allow for missing data, the study planned enrollment of 50 patients.

Secondary end points were summarized as the number and percentage of patients or as the median (interquartile range $[I Q R]$ ) of values by treatment group and/or as between-group differences, and data were reported with Cls. Changes in Ki-67 between pretreatment biopsy and post-treatment surgery were assessed within and between groups using Wilcoxon signed-rank and rank-sum tests, respectively. The analysis of differences in patient-reported FACT-ES summary scores (range, 0 to 76; higher score indicated better function) between treatment groups used linear mixed-effects modeling as a function of postbaseline timepoint and treatment group and controlled for the stratification factors of age (dichotomized as $\leq 39 v \geq 40$ years) and baseline summary score with an autoregressive covariance structure. For each symptom, the proportion of patients who reported a clinically significant symptom level (responses of "quite a bit" or "very much" a problem) ${ }^{14}$ at one or more postbaseline time points was summarized with 90\% Cls. The analysis used SAS 9.4 (SAS Institute, Cary, $\mathrm{NC}$ ), and R version 3.3.1.

\section{RESULTS}

\section{Study Population}

Between February 24, 2014, and January 10, 2017, 51 patients with ER-positive and PgR-positive (ER and PgR $>50 \%$ ), HER2-negative, invasive breast cancer were randomly assigned ( $n=26$ assigned to triptorelin plus letrozole; $n=25$ assigned to degarelix plus letrozole; Fig 1 ). The median age of the patients was 44 years (IQR, 42 to 49 years; Table 1). All patients had an Eastern Cooperative Oncology Group performance status of 0, 49\% had clinically node-positive disease, and $90 \%$ had a ductal histology.

All patients started and completed six cycles of the assigned trial treatment, with the exception of one patient randomly assigned to degarelix plus letrozole who had surgery after three cycles because of progressive disease. Compliance regarding blood draws over time for the enrolled patients was excellent: 502 (99\%) of the 507 blood draws required to assess OFS status over time were obtained.

\section{Endocrine Activity}

By the end of the first cycle (29 days), all patients reached optimal OFS. OFS was reached significantly faster among patients assigned to degarelix plus letrozole than among those assigned to triptorelin plus letrozole (median, $3 \mathrm{v}$ 14 days, respectively; hazard ratio, 3.05); optimal OFS was achieved three times faster with degarelix plus letrozole than with triptorelin plus letrozole $(95 \% \mathrm{Cl}, 1.65$ to 5.65 ; $P<.001$; Fig 2). Notably, optimal OFS was maintained for all patients assigned degarelix plus letrozole during subsequent cycles, whereas $15.4 \%$ of patients assigned triptorelin plus letrozole had suboptimal OFS (E2 level $>2.72$ $\mathrm{pg} / \mathrm{mL}$ ) after cycle 1 (0 events with 119 measurements and six events with 127 measurements, respectively; Fig 3; Appendix Table A1, online only; Appendix Fig A1, online

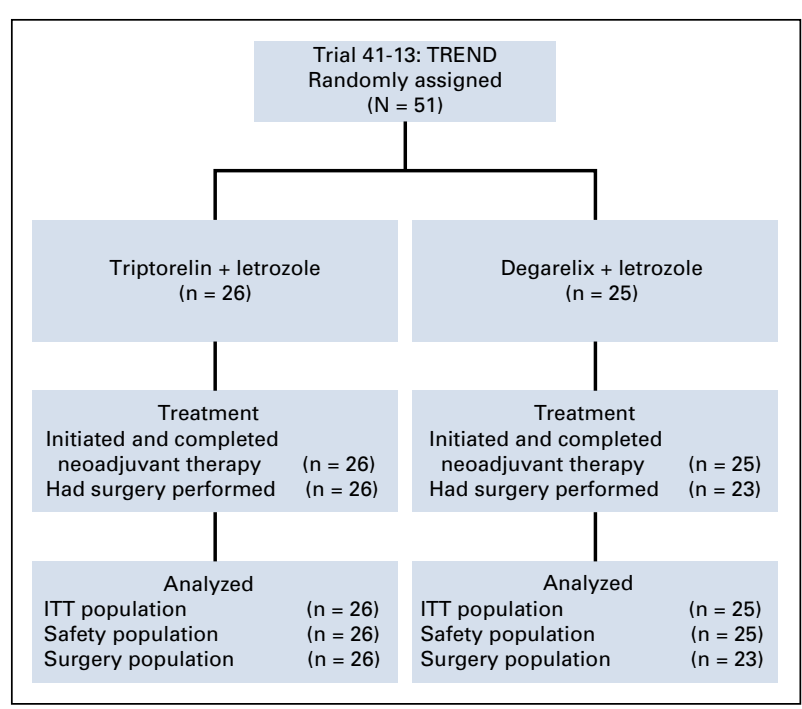

FIG 1. TREND (Trial on the Endocrine Activity of Neoadjuvant Degarelix) CONSORT diagram. ITT, intention to treat. 
TABLE 1. Patient and Pretreatment Disease Characteristics According to Treatment Assignment

Treatment Assignment

\begin{tabular}{|c|c|c|c|}
\hline \multirow{2}{*}{ Characteristic } & & \multirow{2}{*}{$\begin{array}{l}\text { Total } \\
(\mathrm{N}=51)\end{array}$} \\
\hline & Triptorelin + Letrozole $(n=26)$ & Degarelix + Letrozole $(n=25)$ & \\
\hline Median (IQR) & $44(42-48)$ & $45(42-50)$ & $44(42-49)$ \\
\hline Range & $31.0-51.0$ & $26.0-55.0$ & $26.0-55.0$ \\
\hline$\leq 39$ & $4(15.4)$ & $2(8.0)$ & $6(11.8)$ \\
\hline$\geq 40$ & $22(84.6)$ & $23(92.0)$ & $45(88.2)$ \\
\hline Normal $(<25)$ & $15(57.7)$ & $14(56.0)$ & $29(56.9)$ \\
\hline Overweight or obese ( $\geq 25$ ) & $8(30.8)$ & $8(32.0)$ & $16(31.4)$ \\
\hline Unknown & $3(11.5)$ & $3(12.0)$ & $6(11.8)$ \\
\hline Prior oral contraceptive use & $8(30.8)$ & $7(28.0)$ & $15(29.4)$ \\
\hline Never & $21(80.8)$ & $18(72.0)$ & $39(76.5)$ \\
\hline \multicolumn{4}{|l|}{$\mathrm{E} 2, \mathrm{pg} / \mathrm{mL}$ (assessed centrally) } \\
\hline Median (IQR) & $86(57-131)$ & $98(70-194)$ & $94(65-163)$ \\
\hline Range & $21.6-250.0$ & $37.8-404.0$ & $21.6-404.0$ \\
\hline \multicolumn{4}{|l|}{ Histology of biopsy (assessed centrally) } \\
\hline Ductal & $24(92.3)$ & $22(88.0)$ & $46(90.2)$ \\
\hline Lobular & $1(3.8)$ & $2(8.0)$ & $3(5.9)$ \\
\hline Other/unknown & $1(3.8)$ & $1(4.0)$ & $2(3.9)$ \\
\hline \multicolumn{4}{|l|}{ Clinical T stage (by ultrasound) } \\
\hline N1 & $13(50.0)$ & $10(40.0)$ & $23(45.1)$ \\
\hline N2-N3 & $1(3.8)$ & $1(4.0)$ & $2(4.0)$ \\
\hline \multicolumn{4}{|l|}{ ER status of biopsy } \\
\hline Positive (ER > 50\%) & $26(100.0)$ & $25(100.0)$ & $51(100.0)$ \\
\hline \multicolumn{4}{|l|}{ PR status of biopsy } \\
\hline Negative (PgR $\leq 50 \%)$ & $1(3.8)$ & $0(0.0)$ & $1(2.0)$ \\
\hline \multicolumn{4}{|l|}{ HER2 status of biopsy } \\
\hline Negative & $26(100.0)$ & $25(100.0)$ & $51(100.0)$ \\
\hline $\begin{array}{l}\text { Median (IQR) Ki-67 labeling index, \% staining cells of } \\
\text { biopsy* }\end{array}$ & $20(12-30)$ & $16(14-28)$ & $17(12-29)$ \\
\hline Median (IQR) FACT-ES summary score & $69(64-75)$ & $70(66-73)$ & $70(66-74)$ \\
\hline
\end{tabular}

NOTE. Data are presented as No. (\%) unless otherwise specified.

Abbreviations: E2, estradiol; ER, estrogen receptor; FACT-ES, functional assessment of cancer therapy, endocrine subscale; HER2, human epidermal growth factor receptor 2; IQR, interquartile range; Ki-67, protein encoded by the MKI67 gene; PgR, progesterone receptor.

*Ki-67 was determined in a central laboratory. 


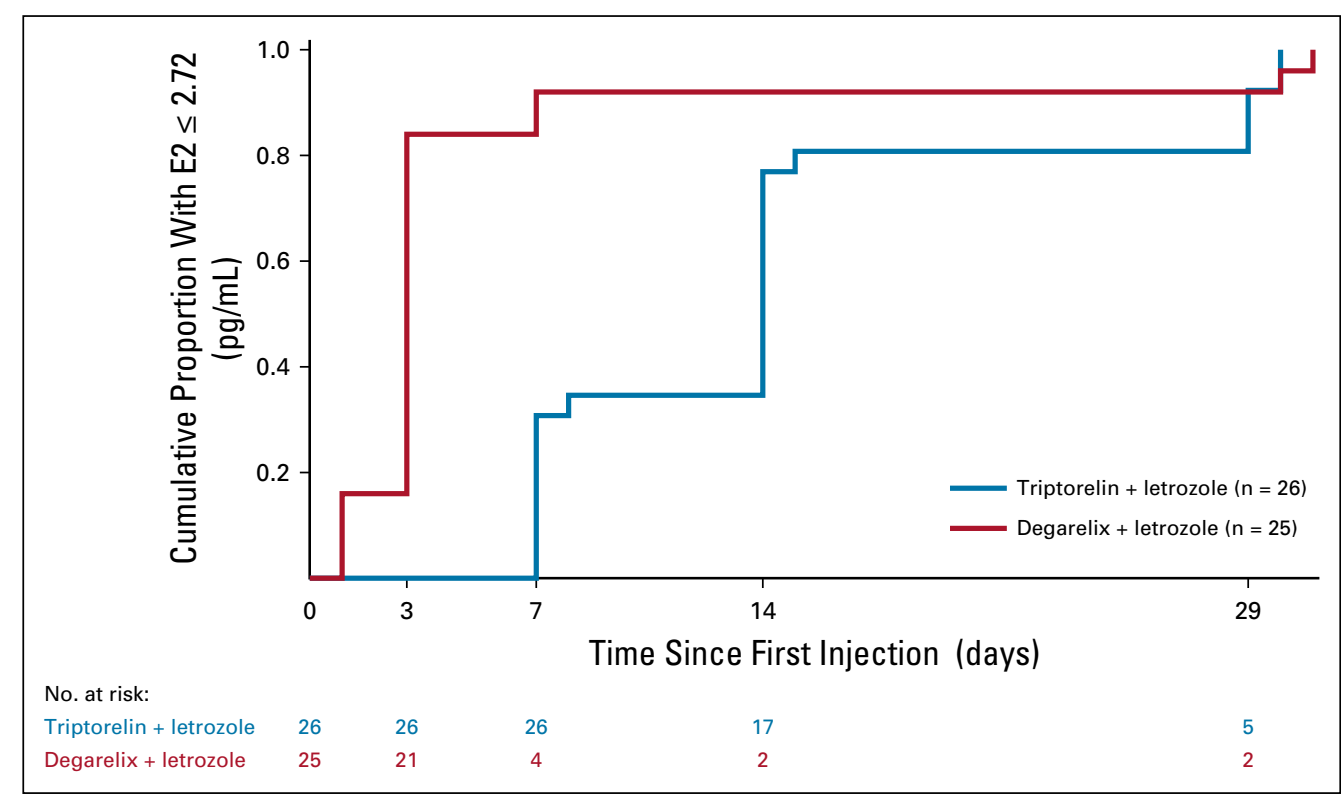

FIG 2. Kaplan-Meier estimates of the cumulative proportions of patients who achieved optimal ovarian function suppression (estradiol [E2] $\leq 2.72 \mathrm{pg} / \mathrm{mL}$ ) according to treatment assignment.

only. FSH and LH over time are summarized in Figure 4 and Appendix Figures A2, A3, and A4 (online only).

\section{Surgery and Pathology}

Forty-nine patients underwent surgery after completion of NET; two patients decided to seek alternative therapies and did not receive surgery within the protocol-suggested time frame. Overall, $38.8 \%$ of patients had node-negative disease at surgery (Table 2). Node-negative disease rates were $43.5 \%$ versus $34.6 \%$ for degarelix plus letrozole versus triptorelin plus letrozole, and the estimated absolute difference was $8.9 \%(90 \% \mathrm{Cl},-14.0 \%$ to $31.8 \%)$. Likewise, BCS rates were $52.2 \%$ versus $42.3 \%$ for degarelix plus letrozole versus triptorelin plus letrozole, and the absolute difference was $9.9 \%(90 \% \mathrm{Cl},-13.5 \%$ to $33.3 \%)$. Thirty percent of patients ( 9 of 30 patients) considered candidates for mastectomy received BCS; 74\% of those considered candidates for BCS at baseline (14 of 19 patients) underwent BCS, whereas the remaining $26 \%$ (five of 19 patients) underwent mastectomy.

The median PEPI score at surgery was 6 (IQR, 4 to 7); only one patient (2.0\%) had a PEPI score of 0 . Ki-67 expression levels were available for all patients on the diagnostic biopsy and for 47 on surgery (excision) samples. Significant reductions in Ki-67 from baseline to surgery were detected within each treatment group (Appendix Fig A5, online only). Median changes were $-10.0 \%(90 \% \mathrm{Cl},-13.5 \%$ to $-5.5 \% ; P=.001$ ) for degarelix plus letrozole and $-9.5 \%$ (90\% Cl, $-15.0 \%$ to $-6.0 \%$; $P=.005$ ) for triptorelin plus letrozole. The changes were not different between the two treatment groups $(P=.55)$.

Overall, $45.1 \%$ of patients had partial responses and $47.1 \%$ had stable disease as best overall response. Objective response rates were $44.0 \%$ versus $46.2 \%$ for degarelix plus letrozole versus triptorelin plus letrozole (difference, $-2.2 \% ; 90 \% \mathrm{Cl},-25.1 \%$ to $20.8 \%$ ). For patients treated with NET, pathologic complete response is less frequent and not the appropriate surrogate of treatment benefit, so it was not a prespecified end point in the trial. We observed only one pathologic complete response in a patient treated with degarelix plus letrozole.

\section{AEs}

There were no treatment-related grade 4 AEs in either treatment group, and there were only two grade 3 AEs (hypertension and anemia) in two patients assigned to triptorelin plus letrozole (Table 3). The most common AEs with degarelix plus letrozole versus triptorelin plus letrozole were hot flashes (80.0\% $v$ 69.2\%), arthralgia $(32.0 \% \vee$ $53.8 \%$ ), insomnia (24.0\% $v 11.5 \%)$, injection site reaction $(24.0 \% \vee 0 \%)$, hypertension (12.0\% v3.8\%), and nausea $(16.0 \% \vee 3.8 \%)$.

\section{Patient-Reported Endocrine Symptoms}

The FACT-ES completion rates were 88\% across assessment time points and were similar between treatment groups. Patients assigned to degarelix plus letrozole reported worse FACT-ES summary scores at each postbaseline time point (Appendix Fig A6, online only) compared with patients assigned to triptorelin plus letrozole. The most burdensome symptoms were hot flashes: $40.0 \%$ of patients who received degarelix plus letrozole and $30.8 \%$ of patients who received triptorelin plus letrozole reported clinically significant levels (Appendix Table A2, online only). Similar proportions in each group were indicated for night sweats. Clinically significant mood swings were noted in $32.0 \%$ of patients who received degarelix plus letrozole and in $11.5 \%$ of patients who received triptorelin plus letrozole. Feeling irritable and joint pains were reported by $24.0 \%$ (for each $A E$ ) of the degarelix- 


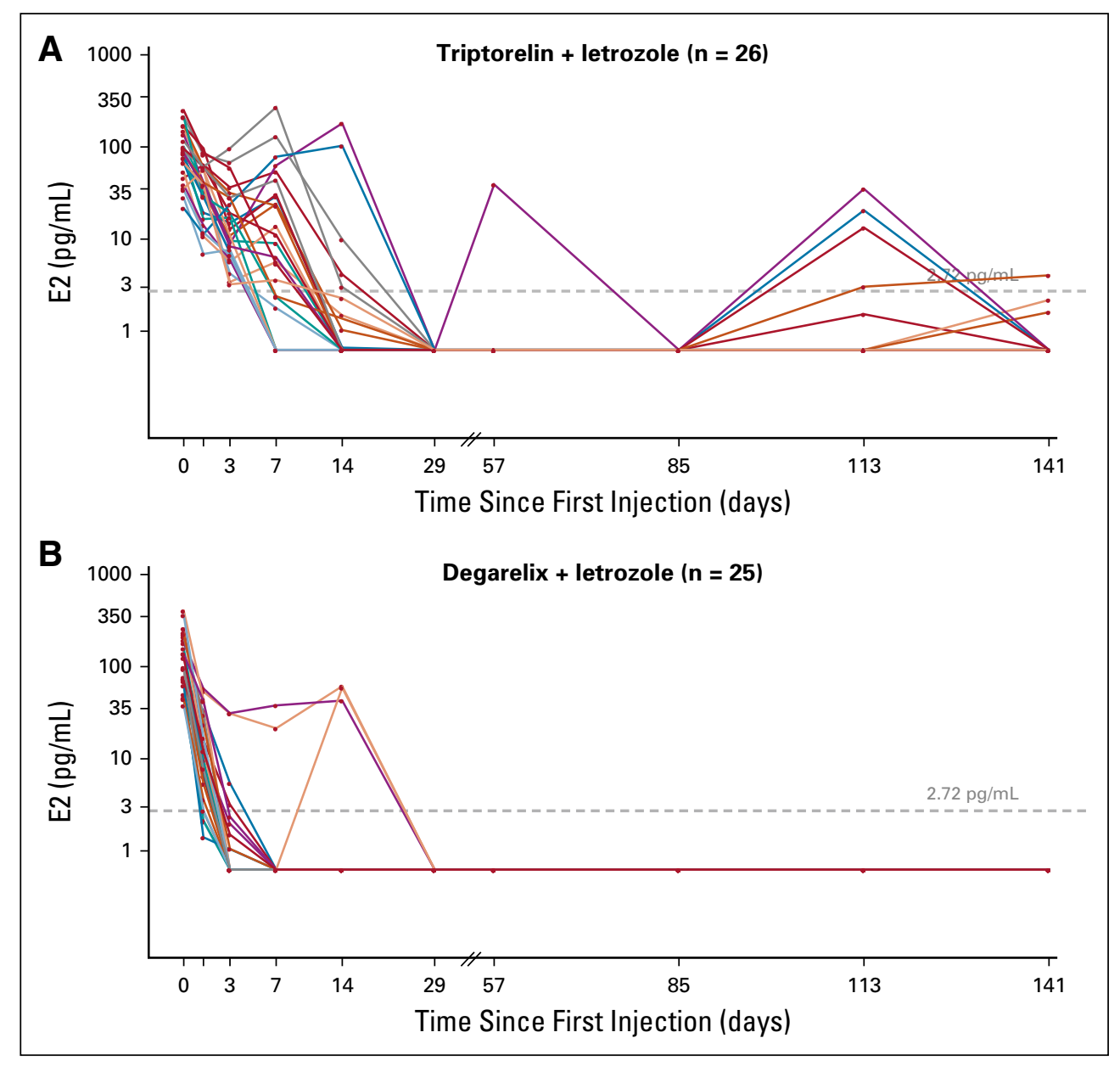

FIG 3. Estradiol (E2; pg/mL) profile over time of 51 patients according to treatment assignment. The $x$-axis corresponds to blood draw time (in days) before (A) triptorelin or (B) degarelix injections ( 0 = before cycle 1 injection; days $29,57,85,113$, and $141=$ before cycles 2 through 6 injections, respectively). The blood draw time scale was adjusted to show the data points in cycle 1 as well as the subsequent cycles in the same figure.

plus-letrozole group and by $11.5 \%$ and $15.4 \%$, respectively, of the triptorelin-plus-letrozole group.

\section{DISCUSSION}

The results of the TREND trial indicate that, in premenopausal patients treated with letrozole as NET for endocrine-responsive breast cancer, degarelix acted faster than triptorelin to induce optimal OFS. Moreover, degarelix ensured maintenance of optimal OFS in all patients during the subsequent (cycles 2 through 6) treatment period, whereas $15.4 \%$ of patients assigned to triptorelin plus letrozole had suboptimal OFS during NET.

These results are consistent with reports of degarelix activity in prostate cancer. ${ }^{7}$ In two phase II dose-finding clinical trials, degarelix 240/160 mg and 240/80 mg were shown to effectively suppress testosterone levels in patients with prostate cancer without testosterone surge or inducement of clinical flare. ${ }^{15,16}$ In another trial, both $240 / 160 \mathrm{mg}$ and 240/80 mg doses were effective and noninferior to leuprolide $7.5 \mathrm{mg}$ in suppression of testosterone. ${ }^{8}$

The maintenance of optimal OFS during degarelix therapy might have significant clinical value in the treatment of premenopausal patients with breast cancer not only in the neoadjuvant setting but also in the adjuvant and metastatic settings. In the adjuvant setting, two recently published clinical trials led to a paradigm shift in the endocrine treatment of premenopausal women. The joint analysis of the SOFT (Suppression of Ovarian Function Trial) and TEXT (Tamoxifen and Exemestane Trial) trials showed that the combination of OFS plus exemestane significantly reduced recurrence compared with OFS plus tamoxifen. ${ }^{17}$ The combination of OFS plus exemestane is currently recommended for patients at intermediate/high risk of relapse together with adjuvant chemotherapy. ${ }^{4,18}$

Bellet et $\mathrm{al}^{19}$ reported that, during the first year of exemestane plus triptorelin in the SOFT trial, $17 \%$ of the patients had E2 levels greater than the threshold of $2.72 \mathrm{pg} / \mathrm{mL}$ (10 pmol/L). Baseline factors related to E2 level greater than $2.72 \mathrm{pg} / \mathrm{mL}$ were no prior chemotherapy $(P=.06)$, higher BMI $(P=.05)$, and lower FSH and LH (each $P<.01) .{ }^{19}$ Other authors reported that approximately $20 \%$ of women do not reach complete OFS with LH-releasing hormone analogs plus Als. ${ }^{6}$ This is consistent with our study, in which $15.4 \%$ of the patients did not maintain OFS during triptorelin treatment. In our trial, the median age was similar to that described in the SOFT and TEXT trials, but most patients were older than age 40 years and therefore less 


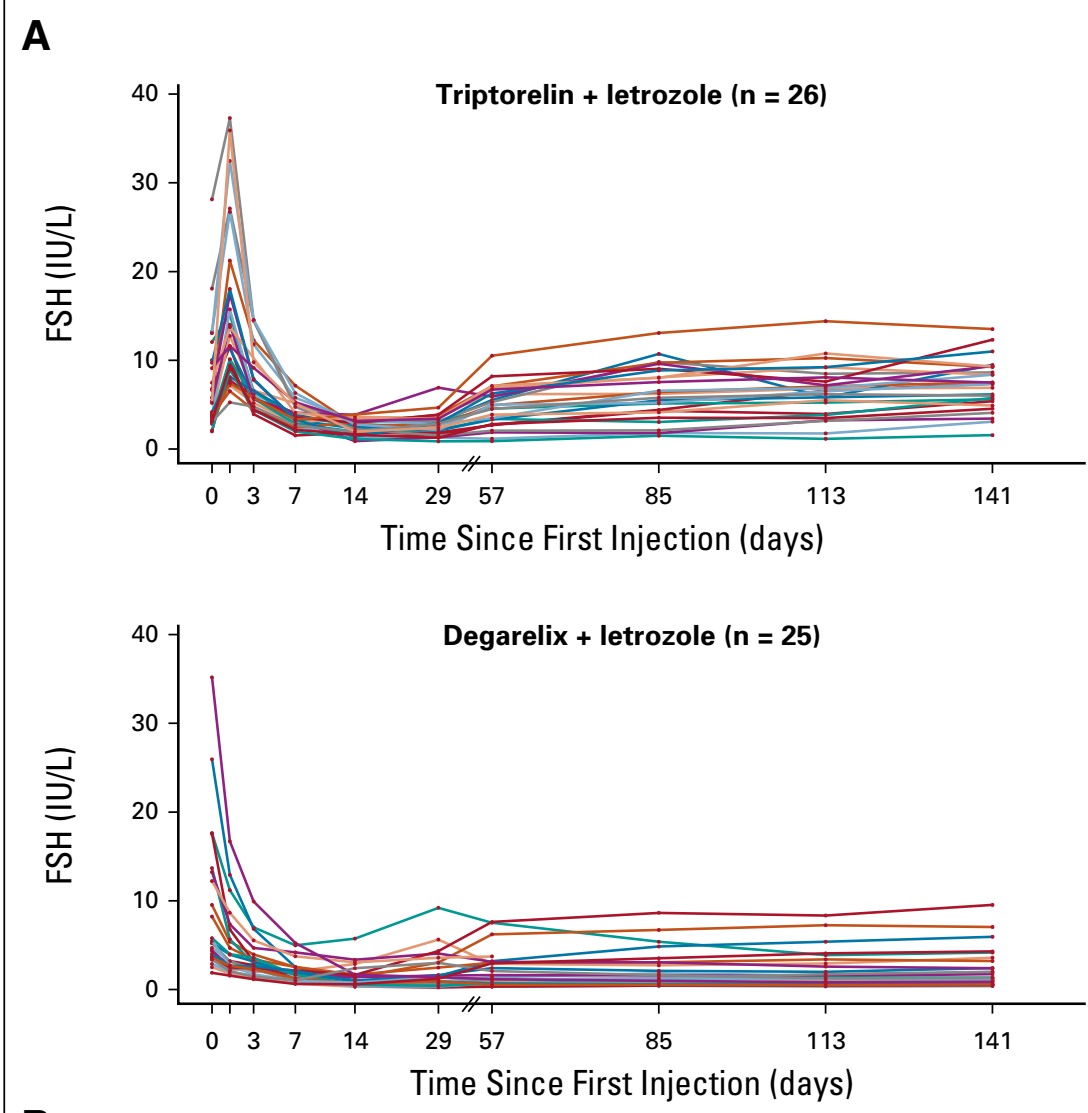

B
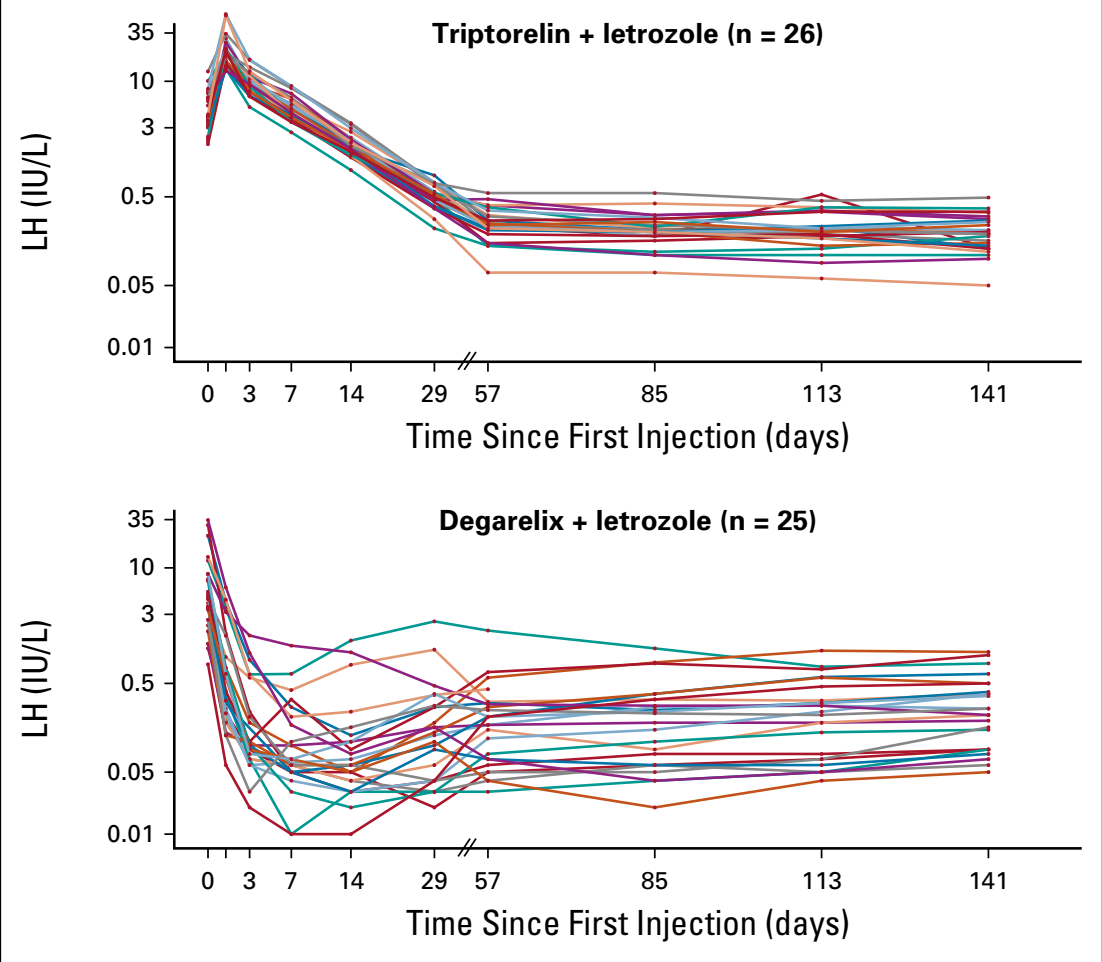

FIG 4. (A) Follicle-stimulating hormone (FSH; IU/L) and (B) luteinizing hormone ( $\mathrm{LH}$; IU/L) profiles over time for 51 patients according to treatment assignment. The $\mathrm{x}$-axis corresponds to blood draw time (in days) before triptorelin or degarelix injections $(0=$ before cycle 1 injection; days $29,57,85,113$, and $141=$ before cycles 2 through 6 injections, respectively). The blood draw time scale was adjusted to show the data points in cycle 1 as well as the subsequent cycles in the same figure. 
TABLE 2. Surgical Pathology Characteristics According to Treatment Assignment

Treatment Assignment

\begin{tabular}{|c|c|c|c|}
\hline \multirow[b]{2}{*}{ Characteristic } & & \multirow[b]{2}{*}{$\begin{array}{c}\text { Total } \\
(\mathrm{N}=49)\end{array}$} \\
\hline & $\begin{array}{l}\text { Triptorelin + Letrozole } \\
\qquad(n=26)\end{array}$ & $\begin{array}{l}\text { Degarelix + Letrozole } \\
\qquad(n=23) \\
\end{array}$ & \\
\hline \multicolumn{4}{|l|}{ Pathologic T stage } \\
\hline $\mathrm{T} 1$ & $8(30.8)$ & $5(21.7)$ & $13(26.5)$ \\
\hline $\mathrm{T} 2$ & $12(46.2)$ & $13(56.5)$ & 25 (51.0) \\
\hline \multicolumn{4}{|l|}{ Pathologic N stage } \\
\hline NO & $9(34.6)$ & $10(43.5)$ & 19 (38.8) \\
\hline N1 & 9 (34.6) & $9(39.1)$ & $18(36.7)$ \\
\hline N2 & $4(15.4)$ & $1(4.3)$ & $5(10.2)$ \\
\hline PEPI score of 0 & $0(0.0)$ & $1(4.3)$ & $1(2.0)$ \\
\hline $\mathrm{pCR}$ & $0(0.0)$ & $1(4.3)$ & $1(2.0)$ \\
\hline
\end{tabular}

NOTE. Data are presented as No. (\%) of patients unless otherwise specified.

Abbreviations: IQR, interquartile range; Ki-67, protein encoded by the MKI67 gene; pCR, pathologic complete response; PEPI, preoperative endocrine prognostic index.

*Ki-67 was determined in a central laboratory.

likely to have ovarian breakthroughs than were younger patients, who showed the greatest benefit from the association of OFS and exemestane in the SOFT and TEXT trials. One could speculate that, in a younger cohort, degarelix could have translated to an even higher percentage of maintained OFS compared with triptorelin. In the presence of incomplete OFS by GnRH analogs, treatment with Als can stimulate the residual ovarian function and lead to an increase in plasma estrogen levels. ${ }^{11}$ Guidelines for the use of adjuvant Als recommend caution when E2 levels determined by highly sensitive/specific methods such as gas chromatography tandem mass spectrometry detection are more than $10 \mathrm{pmol} / \mathrm{L}$ ( $>2.72 \mathrm{pg} / \mathrm{mL}$ ) during treatment with Als, because this indicates that Als are not exerting full effectiveness. ${ }^{11}$

To our knowledge, this is the first report on the use of degarelix in the treatment of women with breast cancer. The toxicity profile of degarelix was as expected, and no safety signals were identified. Most commonly reported AEs were related to $\mathrm{E} 2$ deprivation. The maximum toxicity grade was 2, with the exception of two grade 3 AEs (hypertension and anemia) in two patients assigned to triptorelin plus letrozole. A considerable proportion of patients experienced clinically significant symptom burdens, and higher proportions occurred in patients who received degarelix plus letrozole. The open nature of this study may have affected the $\mathrm{AE}$ reports by patients. On the written trial information, a very common ( $\geq 10 \%$ ) prevalence of hot flushes and injection site AEs was reported for degarelix. Although it is not known how these issues were addressed in the discussion with the patients, it is unlikely that such an effect may explain the different profiles of the patient-reported symptoms. Patients should be made aware of lifestyle interventions and integrative therapies to minimize AEs from endocrine treatment. ${ }^{20}$

In this analysis, higher node-negative disease rates and higher BCS rates were observed for patients assigned to degarelix plus letrozole versus triptorelin plus letrozole. These data compare well with results from the literature. In a cohort of premenopausal patients treated with NET, the overall response rate was $50 \% .^{21}$

Potential limitations of this study are the small number of patients enrolled and the lack of postsurgery follow-up, which did not allow conclusions about the difference in disease outcomes between the treatment groups. In addition, at the time of study design, few similar data were available for breast cancer. The design assumptions of the cumulative optimal OFS rates with triptorelin at time points were based on studies from prostate cancer, 8,22 and the assumptions appeared to be different from those actually observed. Even so, the comparison depends only on rank data (log-rank test), so the study still has good power to detect a relative difference between treatment arms.

Strengths of our study are adherence to protocol requirements (all patients initiated and completed protocol NET), compliance to trial treatments (most patients received triptorelin/degarelix injections during the hospital visits), and central assessment of E2 levels. The study is 
TABLE 3. Patients with Grades 1 to 4 and Grades 3 to 4 Targeted AEs and Other Grades 3 and 4 AEs Reported

AEs by Treatment Assignment and Grade

Triptorelin + Letrozole $(n=26)$

AE by CTCAE version 4

\begin{tabular}{|c|c|c|}
\hline Hot flashes/flushes & 69.2 (51.3 to 83.7) & \\
\hline Arthralgia & 53.8 (36.2 to 70.8 ) & \\
\hline Insomnia & 11.5 (3.2 to 27.2) & \\
\hline Injection site reaction & 0 & \\
\hline Nausea & $3.8(0.2$ to 17.0$)$ & \\
\hline Hypertension & $3.8(0.2$ to 17.0$)$ & 3.8 \\
\hline Fatigue & 11.5 (3.2 to 27.2 ) & \\
\hline Anxiety & 7.7 (1.4 to 22.3 ) & \\
\hline Depression & $3.8(0.2$ to 17.0$)$ & \\
\hline Myalgia & 7.7 (1.4 to 22.3 ) & \\
\hline Vaginal dryness & $3.8(0.2$ to 17.0$)$ & \\
\hline ALT increase & $3.8(0.2$ to 17.0$)$ & \\
\hline Other grades 3 and 4 AEs* & $3.8(0.2$ to 17.0$)$ & 3.8 \\
\hline \multicolumn{3}{|c|}{$\begin{array}{l}\text { NOTE. Data are presented as \% ( } 90 \% \text { exact binomial } \mathrm{CI}) \text {. Thirty-one selected AEs } \\
\text { report form. Only those with at least one reported event are tabulated. } \\
\text { Abbreviations: AE, adverse event; CTCAE, Common Terminology Criteria for Adv } \\
\text { *The other nontargeted grade } 3 \mathrm{AE} \text { was anemia. }\end{array}$} \\
\hline \multicolumn{3}{|c|}{$\begin{array}{l}\text { hypothesis generating and supports larger studies to assess } \\
\text { whether maintenance of OFS with degarelix translates into } \\
\text { a better clinical outcome and is worth a trade-off of in- } \\
\text { creased rate of some AEs. Ongoing clinical trials about NET } \\
\text { in premenopausal patients are investigating novel associ- } \\
\text { ations, }{ }^{20} \text { and will help identify the best candidates for such } \\
\text { treatment as well as possible ways to optimize treatment } \\
\text { efficacy. }\end{array}$} \\
\hline
\end{tabular}

\section{AFFILIATIONS}

${ }^{1}$ IEO, European Institute of Oncology Istituto di Recovero e Cura a Carattere Scientifico (IRCCS), Milan, Italy

${ }^{2}$ Dana-Farber Cancer Institute and Harvard T.H. Chan School of Public Health, Boston, MA

${ }^{3} \mathrm{~S}$ Orsola Hospital, Bologna, Italy

${ }^{4}$ Ospedale Infermi di Rimini, Azienda Unita Sanitaria (AUSL) della Romagna, Italy

${ }^{5}$ International Breast Cancer Study Group Coordinating Center, Bern, Switzerland

${ }^{6}$ Hospital of Prato-AUSL Toscana Centro, Prato, Italy

${ }^{7}$ International Breast Cancer Study Group and University of Sydney, Sydney, Australia

${ }^{8}$ Frontier Science and Technology Research Foundation and Harvard Medical School, Boston, MA

${ }^{9}$ International Breast Cancer Study Group Statistical Center, Dana-Farber Cancer Institute and Harvard Medical School, Boston, MA

\section{CORRESPONDING AUTHOR}

Silvia Dellapasqua, MD, Division of Medical Senology, IEO, European Institute of Oncology IRCCS, Via Ripamonti 435, 20141, Milan, Italy; e-mail: silvia.dellapasqua@ieo.it.
In conclusion, in premenopausal women receiving letrozole for primary treatment of endocrine-responsive breast cancer, OFS was achieved more quickly and maintained more effectively with degarelix than with triptorelin throughout the NET period. These data support additional studies to assess whether degarelix improves disease control compared with the current standard of care in the treatment of premenopausal patients with breast cancer.

\section{PRIOR PRESENTATION}

Presented at the 40th Annual San Antonio Breast Cancer Symposium, San Antonio, TX, December 5-9, 2017.

\section{SUPPORT}

Supported by Ferring (financial and drug supply support) and by the International Breast Cancer Study Group via Frontier Science and Technology Research Foundation, Swiss Group for Clinical Cancer Research, Cancer Research Switzerland, Oncosuisse, Swiss Cancer League, and the Foundation for Clinical Cancer Research of Eastern Switzerland

AUTHORS' DISCLOSURES OF POTENTIAL CONFLICTS OF INTEREST AND DATA AVAILABLITY STATEMENT

Disclosures provided by the authors and data availability statement (if applicable) are available with this article at DOI https://doi.org/10.1200/ JC0.18.00296

\section{AUTHOR CONTRIBUTIONS}

Conception and design: Silvia Dellapasqua, Elisabetta Munzone, Karin Ribi, Jürg Bernhard, Rudolf Maibach, Alan S. Coates, Richard D. Gelber, Meredith M. Regan, Aron Goldhirsch, Marco Colleoni 
Collection and assembly of data: Silvia Dellapasqua, Elisabetta Munzone, Daniela Rubino, Lorenzo Gianni, Harriet Johansson, Giuseppe Viale, Roswitha Kammler, Barbara Ruepp, Aron Goldhirsch, Marco Colleon Data analysis and interpretation: Silvia Dellapasqua, Kathryn P. Gray, Elisabetta Munzone, Harriet Johansson, Karin Ribi, Jürg Bernhard, Manuela Rabaglio-Poretti, Angelo Di Leo, Richard D. Gelber, Meredith M. Regan, Aron Goldhirsch, Marco Colleoni

Provision of study material or patients: Elisabetta Munzone

Administrative support: Barbara Ruepp

Manuscript writing: All authors
Final approval of manuscript: All authors

Accountable for all aspects of the work: All authors

\section{ACKNOWLEDGMENT}

We thank the patients, physicians, nurses, trial coordinators, data managers, and pathologists who participated in the TREND trial. TREND principal investigators and the International Breast Cancer Study Group participants are listed in the Appendix.

\section{REFERENCES}

1. Beatson GT: On the treatment of inoperable cases of carcinoma of the mamma: Suggestions for a new method of treatment. Lancet 2:104-107, 1896.

2. Early Breast Cancer Trialists' Collaborative Group: Ovarian ablation in early breast cancer: Overview of the randomised trials. Lancet 348:1189-1196, 1996

3. Cardoso F, Costa A, Senkus E, et al: 3rd ESO-ESMO international consensus guidelines for advanced breast cancer (ABC 3). Ann Oncol 28:3111, 2017

4. Curigliano G, Burstein HJ. P, Winer E, et al: De-escalating and escalating treatments for early-stage breast cancer: The St Gallen International Expert Consensus Conference on the primary therapy of early breast cancer, 2017. Ann Oncol 28:1700-1712, 2017

5. Lindner $\mathrm{CH}$, Braendle W, Bettendorf G: Endocrine profiles during GnRH-agonist therapy using different application forms. Proceedings of the 13th World Congress of Gynecology and Obstetrics 1991 (abstr 1491)

6. Conte B, Poggio F, Del Mastro L: Luteininzing hormone releasing hormones analogs in combination with tamoxifen for the adjuvant treatment of premenopausal women with hormone receptor-positive breast cancer. Expert Opin Pharmacother 18:1357-1362, 2017

7. National Comprehensive Cancer Network: Clinical practice guidelines in oncology: Prostate cancer V.1.2008. https://www.nccn.org/store/login/login.aspx? ReturnURL=https://www.nccn.org/professionals/physician_gls/pdf/prostate.pdf

8. Klotz L, Boccon-Gibod L, Shore ND, et al: The efficacy and safety of degarelix: A 12-month, comparative, randomized, open-label, parallel-group phase III study in patients with prostate cancer. BJU Int 102:1531-1538, 2008

9. Guerrero-Zotano AL, Arteaga CL: Neoadjuvant trials in ER+ breast cancer: A tool for acceleration of drug development and discovery. Cancer Discov 7:561-574, 2017

10. Masuda N., Sagara Y, Kinoshita T, et al: Neoadjuvant anastrozole versus tamoxifen in patients receiving goserelin for premenopausal breast cancer (STAGE): A double-blind, randomised phase 3 trial. Lancet Oncol 13:345-352, 2012

11. Smith IE, Dowsett M, Yap Y, et al: Adjuvant aromatase inhibitors for early breast cancer after chemotherapy-induced amenorrhea: Caution and suggested guidelines. J Clin Oncol 24:2444-2447, 2006

12. WHO: WHO Handbook for Reporting Results of Cancer Treatment. Geneva, Switzerland, Offset Publication, 1979

13. Fallowfield LJ: Leaity SK, Howell A, et al: Assessment of quality of life in women undergoing hormonal therapy for breast cancer: Validation of an endocrine symptom subscale for the FACT-B. Breast Cancer Res Treat 55:189-199, 1999

14. Fallowfield LJ, Kilburn LS, Langridge C, et al: Long-term assessment of quality of life in the Intergroup Exemestane Study: 5 Years post randomisation. Br J Cancer 106:1062-1067, 2012

15. Van Poppel H, Tombal B, de la Rosette JJ, et al: Degarelix: A novel gonadotrophin-releasing hormone (GnRH) blocker—Results from a one-year, multicentre, randomised, phase 2 dosage-finding study in the treatment of prostate cancer. Eur Urol 54:805-815, 2008

16. Gittelman M, Pommerville PJ, Persson BE, et al: A 1-year, open-label, randomized phase II dose finding study of degarelix, a novel gonadotropin-releasing hormone (GnRH) receptor blocker, in the treatment of prostate cancer in North America. J Urol 180:1986-1992, 2008

17. Pagani O, Regan MM, Walley BA, et al: Adjuvant exemestane with ovarian suppression in premenopausal breast cancer. N Engl J Med 371:107-118, 2014

18. Burstein $\mathrm{HJ}$, Lacchetti $\mathrm{C}$, Anderson $\mathrm{H}$, et al: Adjuvant endocrine therapy for women with hormone receptor-positive breast cancer: American Society of Clinical Oncology Clinical Practice guideline update on ovarian suppression. J Clin Oncol 34:1689-1701, 2016

19. Bellet M, Gray KP, Francis PA, et al: Twelve-month estrogen levels in premenopausal women with hormone receptor-positive breast cancer receiving adjuvant triptorelin plus exemestane or tamoxifen in the Suppression of Ovarian Function Trial (SOFT): The SOFT-EST substudy. J Clin Oncol 34:1584-1593, 2016

20. Lyman GH, Greenlee H, Bohlke K, et al: Integrative therapies during and after breast cancer treatment: ASCO endorsement of the SIO clinical practice guideline. J Clin Oncol 36 2647-2655, 2018

21. Torrisi R, Bagnardi V, Pruneri G, et al: Antitumour and biological effects of letrozole and GnRH analogue as primary therapy in premenopausal women with ER and PgR positive locally advanced operable breast cancer. Br J Cancer 97:802-808, 2007

22. Heyns CF, Simonin MP, Grosgurin P, et al: Comparative efficacy of triptorelin pamoate and leuprolide acetate in men with advanced prostate cancer. BJU Int 92:226-231, 2003 
Neoadjuvant Degarelix Versus Triptorelin in Premenopausal Patients Who Receive Letrozole for Locally Advanced Endocrine-Responsive Breast Cancer: A Randomized Phase II Trial

The following represents disclosure information provided by authors of this manuscript. All relationships are considered compensated. Relationships are self-held unless noted. I = Immediate Family Member, Inst = My Institution. Relationships may not relate to the subject matter of this manuscript. For more information about ASCO's conflict of interest policy, please refer to www.asco.org/rwc or ascopubs.org/jco/site/ifc.

Silvia Dellapasqua

Travel, Accommodations, Expenses: Ipsen

Kathryn P. Gray

Stock and Other Ownership Interests: DVAX

Elisabetta Munzone

Consulting or Advisory Role: Pierre Fabre

Lorenzo Gianni

Consulting or Advisory Role: Celgene, AstraZenecaTravel, Accommodations, Expenses: Roche, Genentech, Novartis, Pfizer

Giuseppe Viale

Honoraria: MSD Oncology

Consulting or Advisory Role: Dako, Roche, Genentech, AstraZeneca, BristolMyers Squibb, Astellas Pharma

Research Funding: Roche, Genentech, Ventana Medical Systems (Inst)

Travel, Accommodations, Expenses: Roche, Celgene

Rudolf Maibach

Honoraria: Fennec Pharma

Travel, Accommodations, Expenses: Fennec Pharma

\section{Angelo Di Leo}

Honoraria: Roche, Novartis, Pfizer, AstraZeneca, Genomic Health, Eisai, Lilly, Pierre Fabre, Bayer, Celgene, Amgen

Consulting or Advisory Role: Roche, Novartis, Pfizer, AstraZeneca, Pierre Fabre, Lilly, Bayer, Celgene, Puma Biotechnology, Daiichi Sankyo, Ipsen, Genomic Health, Genentech, Amgen, Eisai

Research Funding: Novartis, Pfizer, AstraZeneca

Travel, Accommodations, Expenses: Roche, Novartis, Pfizer, AstraZeneca, Eisai, Bayer, Celgene, Lilly, Pierre Fabre, Buma Biotechnology, Daiichi Sankyo

\section{Richard D. Gelber}

Research Funding: AstraZeneca (Inst), Novartis (Inst), Roche (Inst), Celgene (Inst), Merck (Inst), Pfizer (Inst), Ipsen (Inst), Ferring (Inst)

\section{Meredith M. Regan}

Consulting or Advisory Role: Merck, Ipsen (Inst)

Research Funding: Veridex (Inst), OncoGenex (Inst), Pfizer (Inst), Ipsen (Inst), Novartis (Inst), Merck (Inst), Ferring (Inst), Celgene (Inst), AstraZeneca (Inst), Pierre Fabre (Inst), Ipsen (Inst), Bayer (Inst), Bristol-Myers Squibb (Inst), Roche (Inst)

Travel, Accommodations, Expenses: Bristol-Myers Squibb

Marco Colleoni

Honoraria: Novartis

Consulting or Advisory Role: Pierre Fabre, Pfizer, OBI Pharma, Puma Biotechnology, Celldex, AstraZeneca

No other potential conflicts of interest were reported. 
TREND (Trial on the Endocrine Activity of Neoadjuvant Degarelix) Investigators and International Breast Cancer Study Group Participants

International Breast Cancer Study Group (IBCSG) Scientific Committee M. Colleoni (Chair), A. Di Leo (Co-chair)

IBCSG Scientific Executive Committee: M. Colleoni, A. Di Leo, F. Boyle, G. Jerusalem, M. Regan, G. Viale

IBCSG Foundation Council: R. Stahel (President), S. Aebi, F. Boyle, A. Coates, M. Colleoni, A. Di Leo, R. Gelber, A. Goldhirsch, G. Jerusalem, P. Karlsson, I. Kössler, M. Regan

IBCSG Coordinating Center, Bern, Switzerland: A. Hiltbrunner (Director), Y. Chittazhathu Kurian Kuruvilla, S. Fournarakou, L. Fritzsche, A. Gasca, R. Kammler, R. Maibach, R. Pfister, M. Rabaglio, M. Weber IBCSG Monitors: G. Achille, D. Celotto
IBCSG Statistical Center, Department of Biostatistics and Computational Biology, Dana-Farber Cancer Institute, Boston, MA: M. Regan (Director), R. Gelber, K. Gray, H. Huang, C. Mahoney, K. Price

IBCSG Data Management Center, Frontier Science and Technology Research Foundation, Amherst, NY: L. Blacher (Director), K. Scott (Data Management Section Head), H. Shaw (Lead Trial Coordinator), M. Blackwell, R. Starkweather, A. Cesario, A. Dickinson, V. Palermo IBCSG Quality of Life Office, Bern, Switzerland: J Bernhard, K Ribi

IBCSG Central Pathology Office, European Institute of Oncology, Division of Pathology, Milan, Italy: G. Viale (Director), S. Andrighetto, G. Bardeli, F. Ciocca, P. Dell'Orto, L. Russo

\section{Participating Centers and Principal Investigators}

Istituto Europeo di Oncologia, Milano, Italy: M. Colleoni

Ospedale S. Orsola-Malpighi, Bologna, Italy: C. Zamagni

Ospedale Infermi di Rimini, Rimini, Italy: L. Gianni

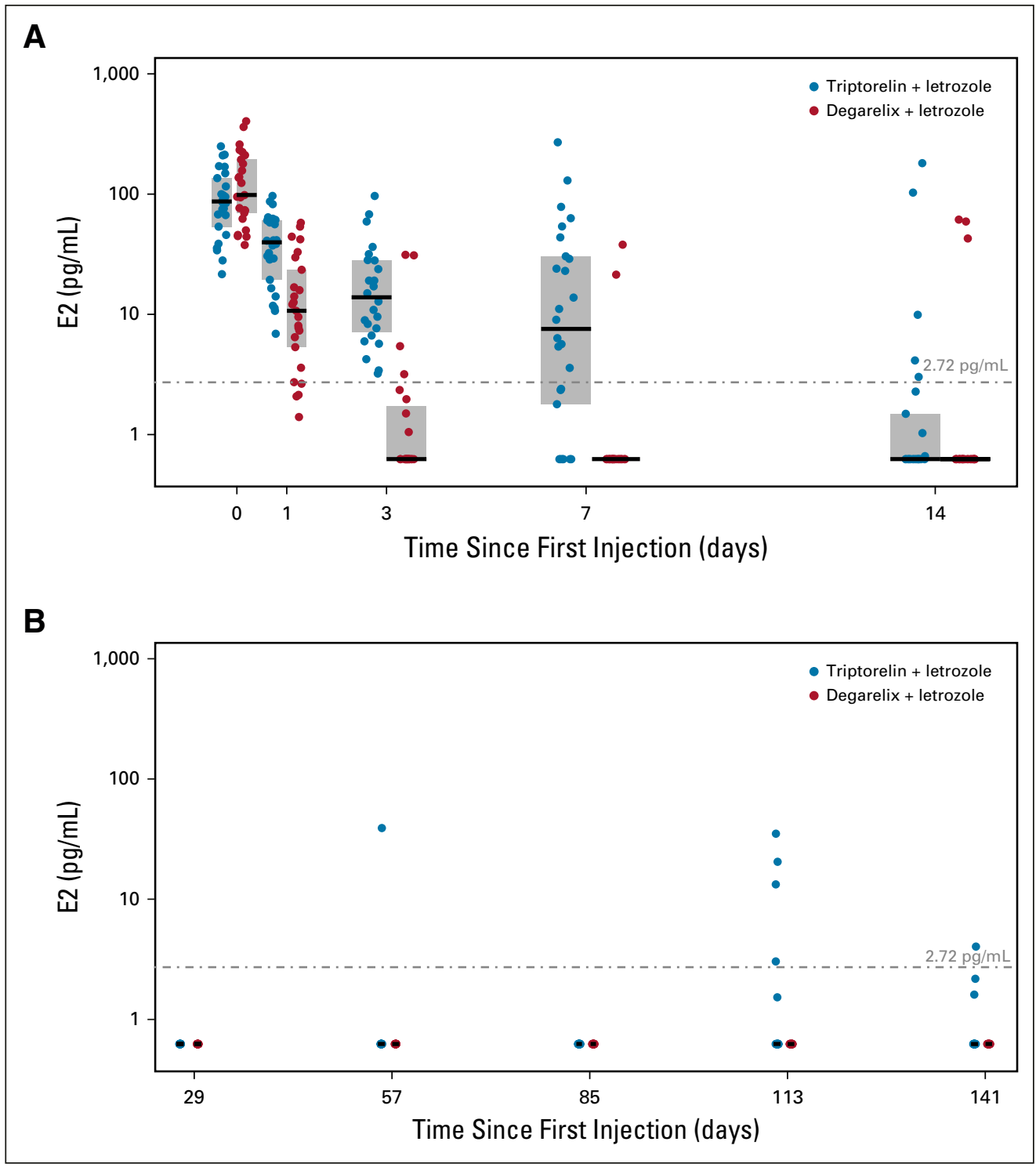

FIG A1. Distributions of estradiol (E2) levels over time according to treatment assignment. (A) Days 0 to 14 of cycle 1; (B) days 29 to 141 (before injection at cycles 2 to 6). The gray line corresponds to E2 threshold of $2.72 \mathrm{pg} / \mathrm{mL}$. 


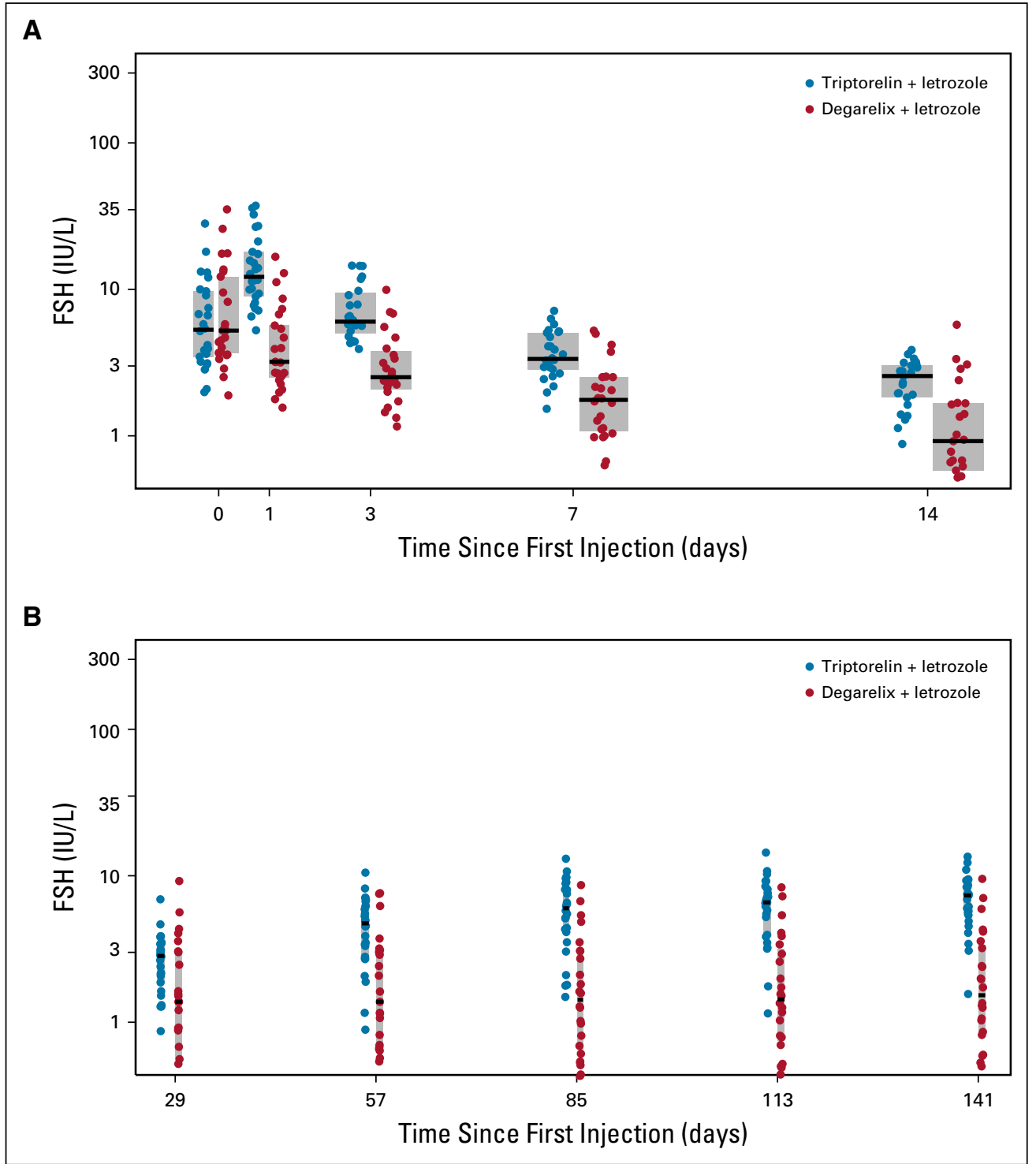

FIG A2. Distributions of follicle-stimulating hormone (FSH) levels over time according to treatment assignment. (A) Days 0 to 14 of cycle 1; (B) days 29 to 141 (before injection at cycles 2 to 6). 


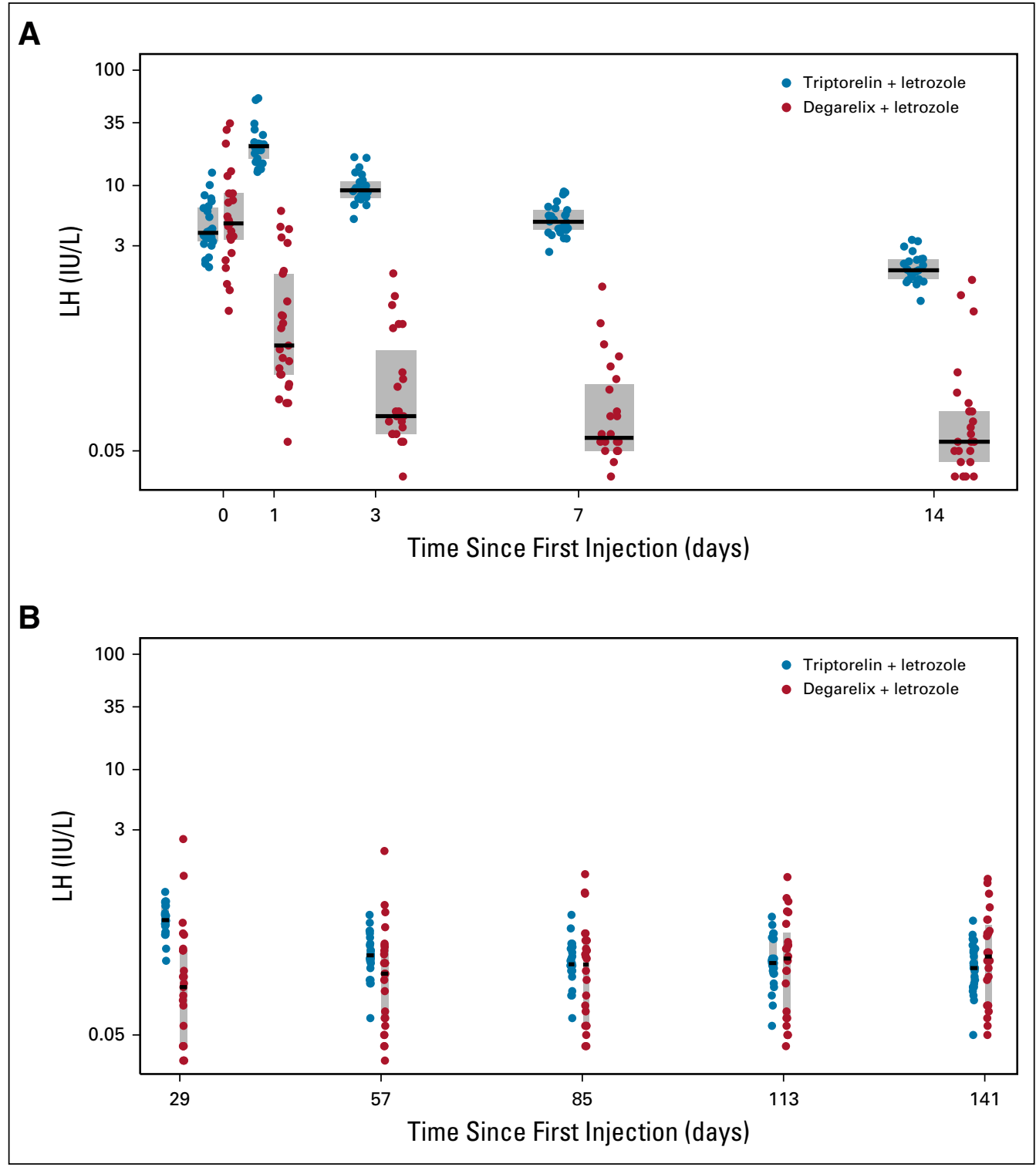

FIG A3. Distributions of luteinizing hormone (LH) levels over time according to treatment assignment. (A) Days 0 to 14 of cycle 1 ; (B) days 29 to 141 (prior to injection at cycles 2 to 6). 


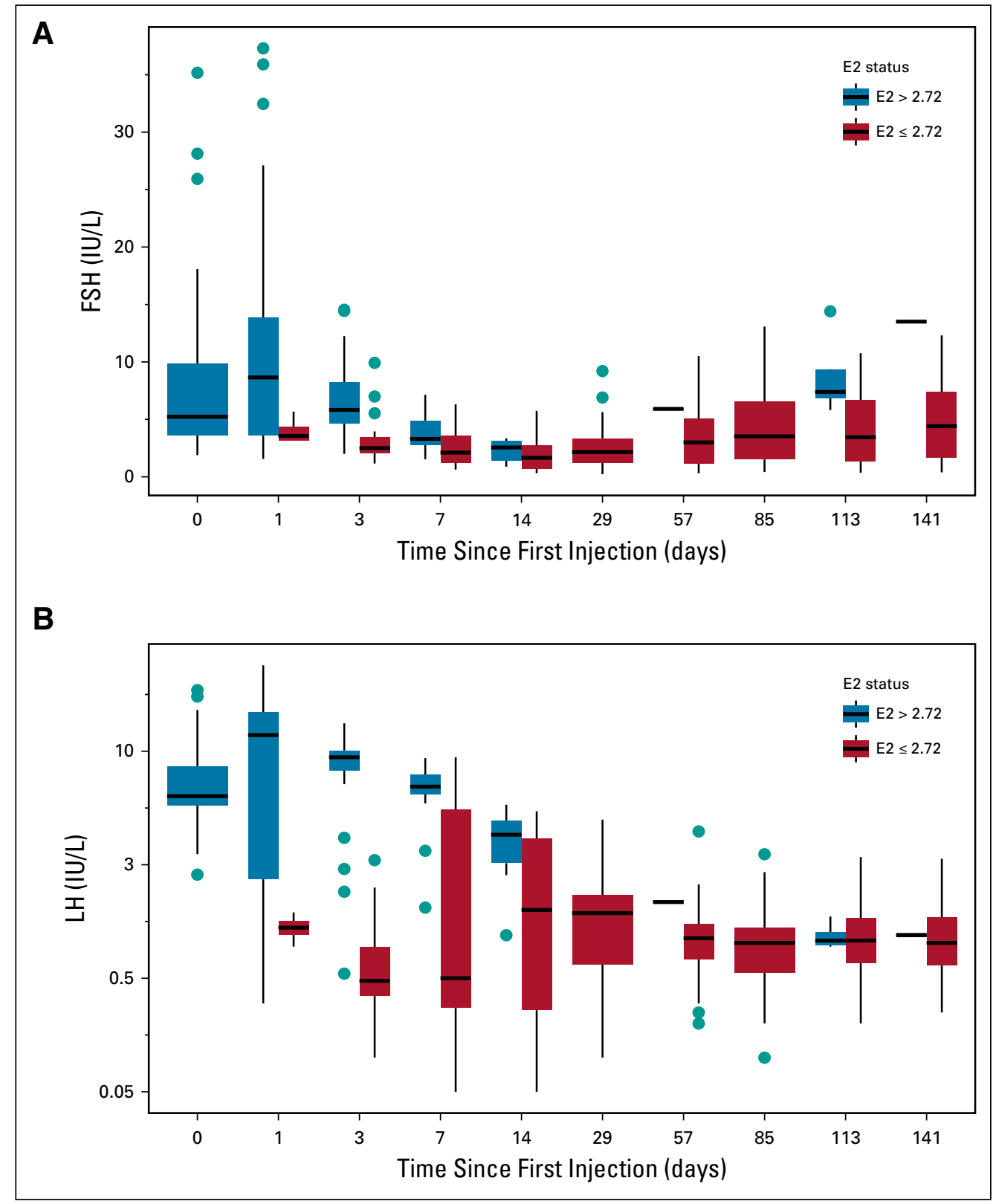

FIG A4. Correlation of (A) follicle-stimulating hormone (FSH) and (B) luteinizing hormone (LH) levels with estradiol (E2) status (E2 $\leq 2.72 \mathrm{pg} / \mathrm{mL}$ to reach ovarian function suppression [OFS] $v$ E2 $>2.72 \mathrm{pg} / \mathrm{mL}$ for suboptimal OFS) over time. 


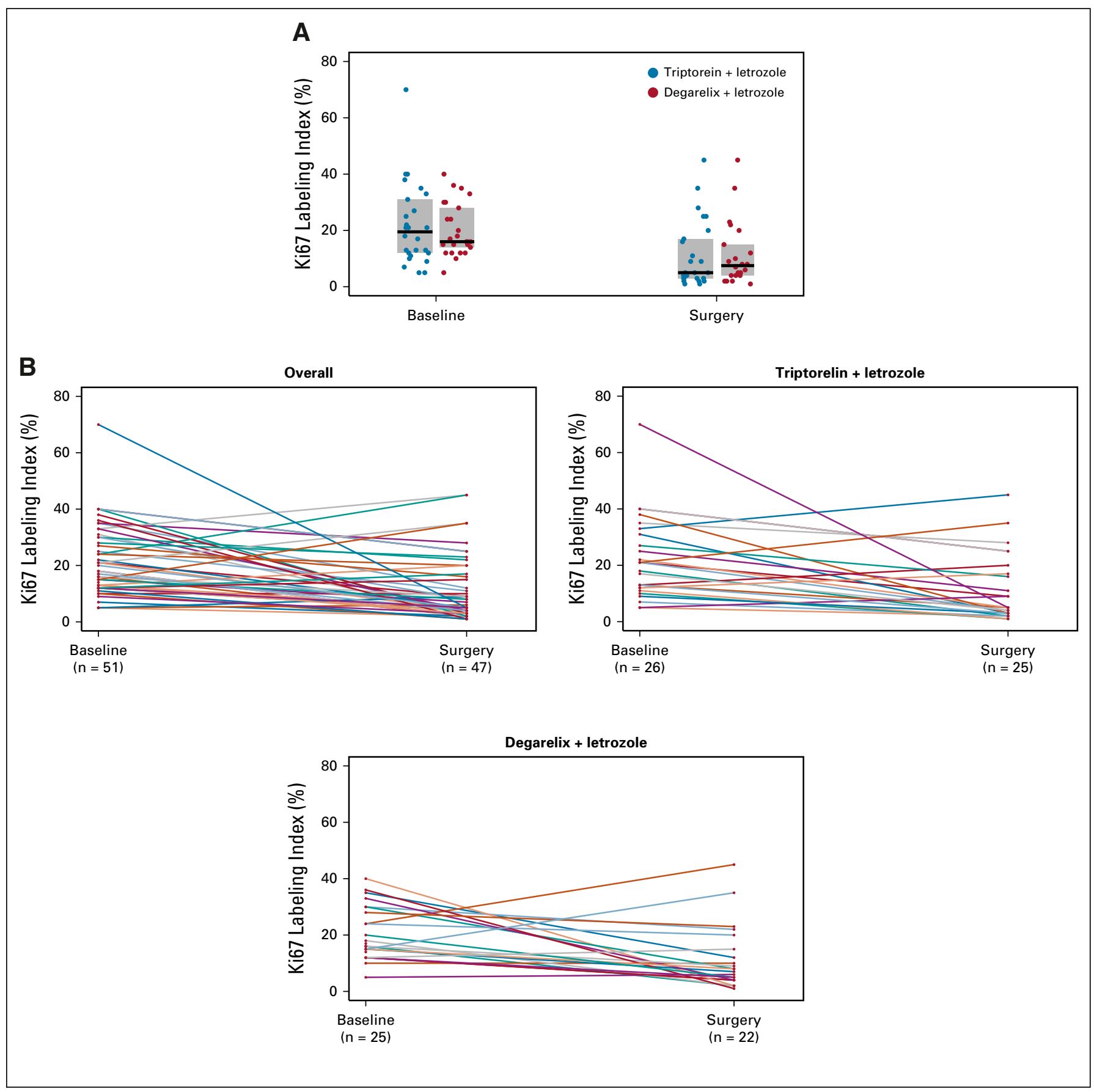

FIG A5. Ki67 (protein encoded by the MIK67 gene) labeling index (\%) at baseline (pre-treatment biopsy) and at surgery (residual disease). (A) Distributions of Ki67 according to time point and treatment assignment. (B) Changes in Ki67 between time points for individual participants, overall and according to treatment assignment. 


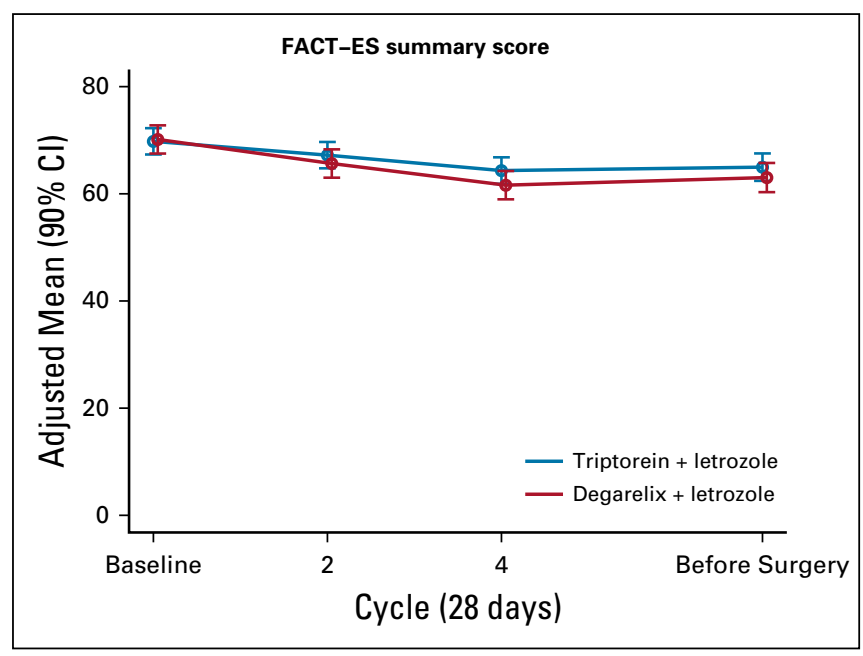

FIG A6. Functional assessment of cancer therapy, endocrine subscale (FACT-ES), summary scores (range, 0 to 76; higher score denotes better functioning) at baseline and during neoadjuvant endocrine therapy. FACT-ES was completed before the first injection and on day 1 of cycles 2 and 4 as well as before surgery. Plots are the adjusted means with $90 \% \mathrm{Cls}$.

TABLE A1. Percentage of Patients' E2 Levels $\leq 2.72 \mathrm{pg} / \mathrm{mL}$ During Time Points of the First Cycle According to Treatment Assignment

Blood Draw Time (days since first injection)

\begin{tabular}{|c|c|c|c|c|c|c|}
\hline \multirow[b]{2}{*}{ Variable } & \\
\hline & 0 & 1 & 3 & 7 & 14 & $29 *$ \\
\hline \multicolumn{7}{|l|}{ Triptorelin + letrozole } \\
\hline No. with E2 measurement & 26 & 26 & 24 & 26 & 25 & 25 \\
\hline No. (\%) with E2 $\leq 2.72 \mathrm{pg} / \mathrm{mL}$ & $0(0)$ & $0(0)$ & $0(0)$ & $9(35)$ & $20(80)$ & $25(100)$ \\
\hline \multicolumn{7}{|l|}{ Degarelix + letrozole } \\
\hline No. (\%) with E2 $\leq 2.72 \mathrm{pg} / \mathrm{mL}$ & $0(0)$ & $4(16)$ & $20(83)$ & $22(92)$ & $22(88)$ & $25(100)$ \\
\hline
\end{tabular}

Abbreviation: E2, estradiol; C, cycle; d, day.

*Blood draw was before $\mathrm{C} 2$ injection. 
TABLE A2. Percentage of Patients Who Experienced Clinically Significant FACT-ES Individual Item Score at Any Time During Neoadjuvant Treatment by Treatment Assignment

Treatment Assignment

\section{FACT-ES Item}

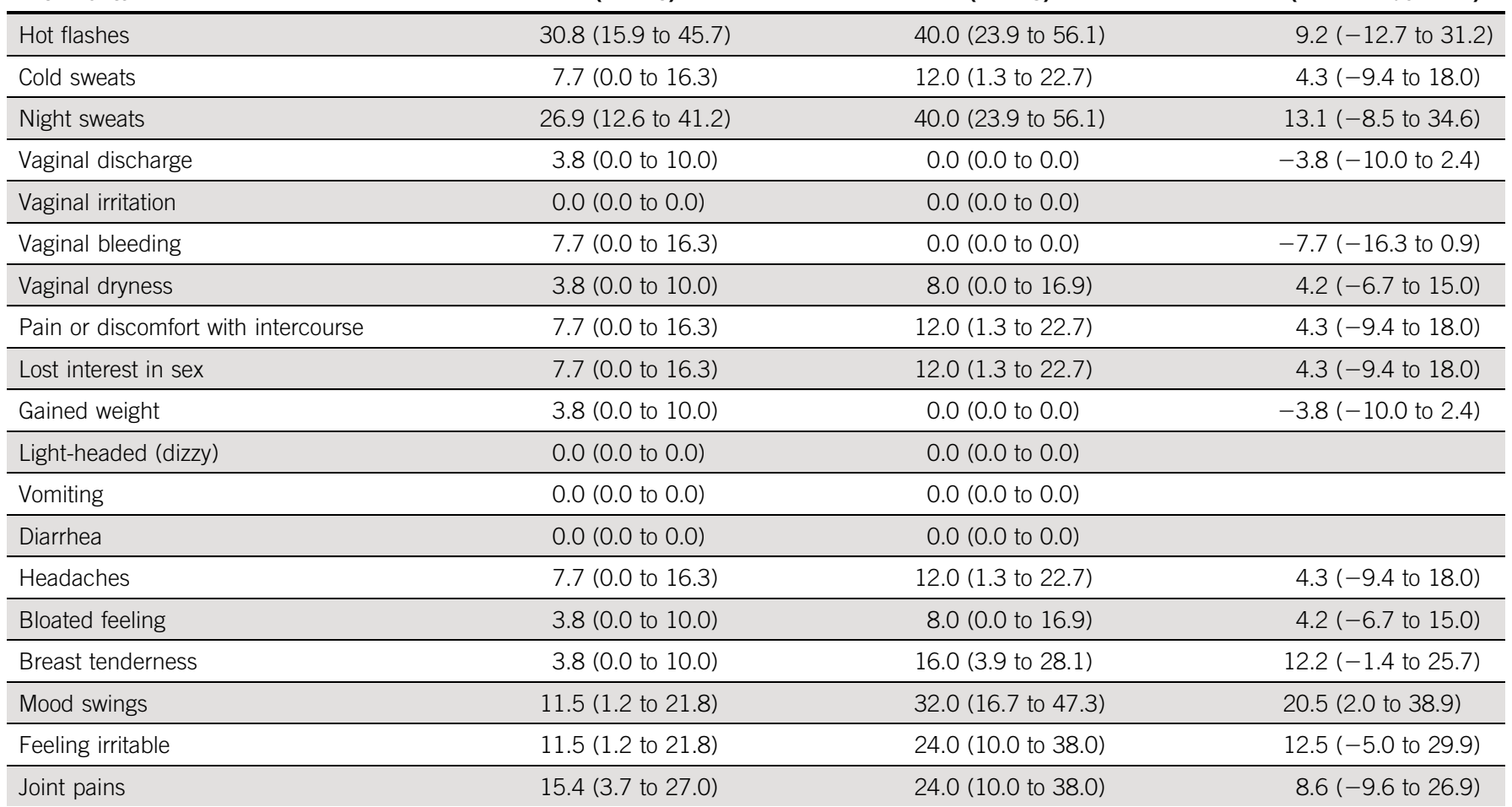

NOTE. Percentages are reported as No. $(90 \% \mathrm{CI})$. Item scores were "quite a bit" or "very much" a problem. Abbreviation: FACT-ES, functional assessment of cancer therapy, endocrine subscale. 